\title{
INVESTIGATION OF NEO ASTEROIDS 2006 VB14 AND 1986 DA
}

\author{
I. Eglitis \\ Institute of Astronomy, University of Latvia, Raina blvd. 19, Riga, LV 1586, Latvia, \\ ilgmars.eglitis@lu.lv
}

\begin{abstract}
. 566 positions and photometric observations of NEO objects 2006 VB14 = Y5705 = 345705 and 1986 DA were obtained with Baldone Schmidt telescope in 2018 and 2019, to detecting rotation period and other physical characteristics. A Fourier transform was applied to determine the rotation period for asteroid 1986 $\mathrm{DA}=6178$. Value $3.12 \pm 0.02 \mathrm{~h}$ was obtained. Observations confirm the previously obtained rotation period $\mathrm{P}=3.25 \mathrm{~h}$ for 2006 VB14.
\end{abstract}

Keywords: NEO - asteroids - rotation periods

АНОТАЦІЯ. 566 позиційних та фотометричних спостережень об'єктів NEO - 2006 VB14 = Y5705 = 345705 та 1986 DA - отримано за допомогою телескопа Балдона Шмідта у 2018 та 2019 роках для виявлення періоду обертання та інших фізичних характеристик. Для визначення періоду обертання астероїда 1986 DA=6178 було застосовано перетворення Фур'є. Отримали значення $3.12 \pm 0.02$ год. Спостереження підтверджують раніше отриманий період обертання $\mathrm{P}=3.25$ год. для 2006 VB14.

Ключові слова: NEO - астероїди - періоди обертання

\section{Introduction}

The surfaces of smallest planets and moons of the Solar system are covered with large number of craters created by asteroids. Every day, Earth is bombarded with more than 100 tons of dust and millimeter-sized particles from space. About once a year, a two meter sized asteroid hits Earth's atmosphere, often creating a bolide event as the friction of the Earth's atmosphere causes them to disintegrate - sometimes explosively. About every five year Chelaybinsk type event take part. The largest impact during this 20-year interval was the recent daytime Chelyabinsk event $(440,000-500,000$ tons of TNT) recorded over central Russia on February 15, 2013. This small asteroid that exploded in the atmosphere near Chelyabinsk, Russia was about 16 meters in size before it hit the Earth. While that impact focused public attention on the potential hazards of NEO impacts with Earth, space scientists have long known that such events are just a part of Earth's geologic history. Scientific assessments of the risk of, as well as the hazards posed by, future asteroid impacts with Earth vary. In an article published in Nature (2013) by Peter Brown and his colleagues reported that "telescopic surveys have only discovered about 500 near-Earth asteroids that are 10-20 meters in diameter (comparable to the
Chelyabinsk asteroid) of an estimated near-Earth asteroid population of around 20 million, implying that a significant impactor population at these sizes could be present but not yet cataloged in the discovered near-Earth asteroid population (Brown et al., 2013). The importance of the small body studies in the Solar system can be properly evaluated if we recall the volcanic eruption effects in Iceland, comparable to the effect caused by the fall of a small asteroid. The fall of an asteroid larger than $50 \mathrm{~m}$ will be a disaster that can stop the progress in the world for several years, but the fall of a $300 \mathrm{~m}$ and larger body can terminate the development of civilization on the Earth for several decades, or even destroy the humanity at all. At the 5th meeting of the PECS Committee in on 27 of May 2009 in Esrin (Italy), the total number of NEO and hazard asteroids, is assessed as 66000 (Bobrinsky, 2009). NASA congress on 5 of March 2007 provided the assessment of the problem in Near-Earth Object Survey and Deflection Analysis of Alternatives. It concluded that only the wide ground base plus space sensor observations of Venus, like the orbit, can allow a more prompt solution of the problem, i.e. to discover the NEO asteroids (up to 90\%) in the nearest future (Milani et al., 2012). Finally, the research of asteroids manages to draw vast attention of mass media, thus promoting the awareness of the importance of science, including astronomy, among public at large, young people in particular. From the other point of view the investigation of asteroids properties are important for development of evolution theory of the Solar system and classification of small objects in the Solar system. Photometric study of light curves can obtain additional information about size, rotation period, structure of objects, existence of craters and ice fields on the surface, which is very important data for space missions and for fantastic ideas about mining of minerals on asteroids. The Earth was not formed in a radial location where water can directly condense. Water must have been delivered to the Earth from "elsewhere": exogenically, i.e., from asteroids and comets, or else endogenically, i.e., from accreting water-absorbed bodies. It is another motive to perform the research of the small bodies in the Solar system.

\section{Observation}

Observations of NEO asteroids were made in 20182019 with $16.8 \mathrm{Mb}$ camera STX-16803 installed on Baldone Schmidt telescope. Baldone. Schmidt has $1.2 \mathrm{~m}$ main mirror, correction lens $80 \mathrm{~cm}$, focal length $2.4 \mathrm{~m}$.

In 2018, 1028 CCD images were obtained covering 200 square degrees of sky and 7 new asteroids were discov- 
ered. Common number of observed asteroids was 826 . Baldone observatory work at high declinations $(\delta>50$ degrees), because the sky covering in this region is very weak (see Sky coverage map at https://www.minorplanetcenter.net/iau/SkyCoverage.html). Without monitoring of asteroids the purpose of this research were obtaining the light curves of 2006 VB14 and 1986 DA in order to determine theirs rotational period. 566 positions and photometric observations of NEO objects 2006 VB14 = Y5705 = 345705 and 1986 DA were obtained, to detecting rotation period and other physical characteristics. Description of obtained images is given in Table 1 .

Table 1. NEO asteroids observed at the Baldone Astrophysical Observatory.

\begin{tabular}{|l|l|}
\hline Object/Date & $\begin{array}{l}\text { Number of CCD } \\
\text { imagies }\end{array}$ \\
\hline 2006 VB $14=345705$ & \\
\hline 14.10 .2018 & 3 \\
\hline 17.10 .2018 & 3 \\
\hline $17 / 18.10 .2018$ & 53 \\
\hline $04 / 05.11 .2018$ & 40 \\
\hline $28 / 29.11 .2018$ & 125 \\
\hline $29 / 30.11 .2018$ & 108 \\
\hline $30.11 / 01.12 .2018$ & 90 \\
\hline 1986 DA $=6178$ & \\
\hline $16 / 17.04 .2019$ & 27 \\
\hline $17 / 18 / .04 .2019$ & 25 \\
\hline $22 / 23 / 04.2019$ & 23 \\
\hline $28 / 29.04 .2019$ & 34 \\
\hline $05 / 06.05 .2019$ & 21 \\
\hline
\end{tabular}

\section{Processing of CCD images}

In order to reduce the images, flats, bias, and dark calibration images were taken each night. The program Maxim DL was used to reduce and align the images. The flat-field images were taken against the twilight sky. The darks were exposed for the same time as the respective light images, two or three minutes for both asteroids. The red filter was used for observation.

Afterward, the program MPO Canopus v10.2.1.0 (Warner, 2011) was used to perform differential photometry on the reduced data. For each data set, five stars were used for brightness comparison to the asteroid. Aperture photometry using a differential photometry technique was done to determine the brightness of comparison stars and the asteroid. The errors in magnitude for stars and asteroids were found and plotted in a phase diagram. Relative magnitude (the difference between brightness and average day brightness of asteroid) versus rotation phase form light curve. 339 brightness measurements of 2006 VB14 and 130 for 1986 DA were obtained using "g" GAIA magnitudes of more than 30 reference stars.

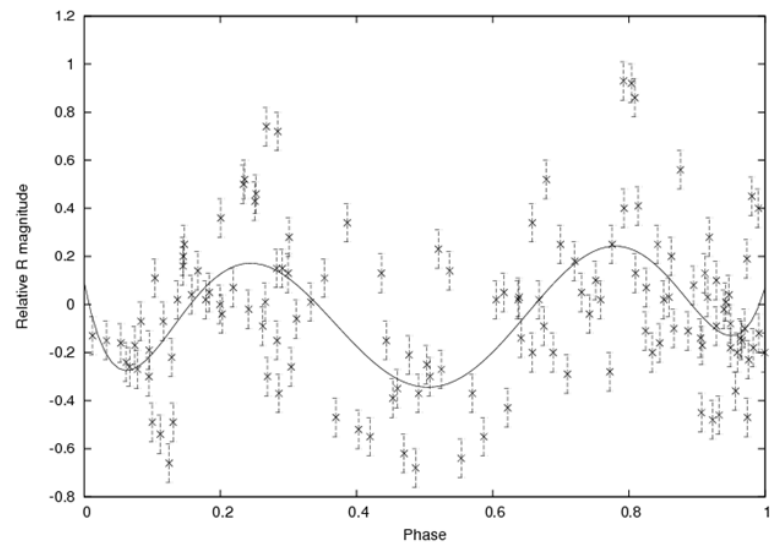

Figure 1: Light curve for NEO 2006 VB14.

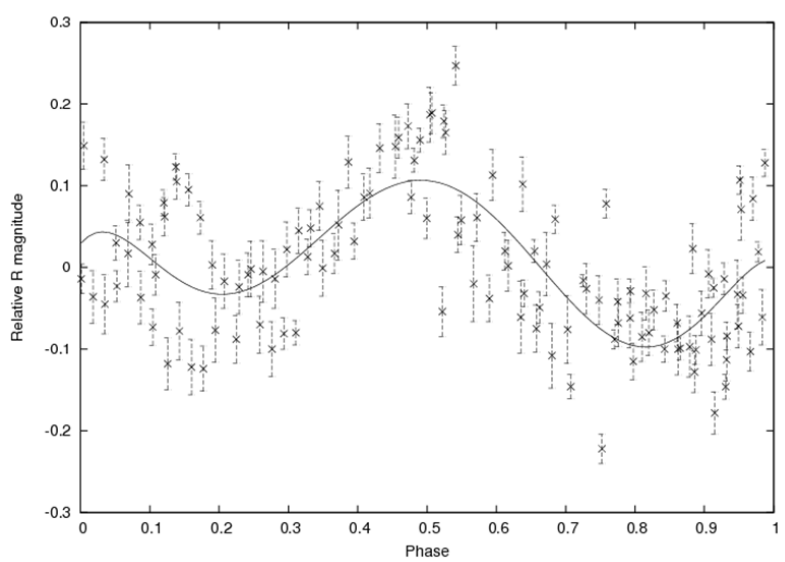

Figure 2: Light curve for NEO 1986 DA.

\section{Results}

A Fourier transform was applied to determine the rotation period for both asteroids. Light curves were created also using MPO Canopus software.

The rotation period $3.25 \pm 0.02 \mathrm{~h}$ better fitted to our measurements for $2006 \mathrm{VB} 14$. The period is in agreement with the earlier work of Skiff et al. 2012. The sharp fall of brightness in phases 0.3 and 0.8 and the brightness peak in phase 0.1 , indicate on possible presence of a crater and the bright surface area (frozen gas field or water) on the asteroid surface, respectively.

The rotation period $3.25 \pm 0.02 \mathrm{~h}$ better fitted to our measurements for 1986 DA. The similar reduction and processing procedure was used for $130 \mathrm{CCD}$ images of asteroid 1986 DA. A Fourier transform was then applied to determine the rotation period. A Fourier transform was then applied to determine the rotation period. Value $3.12 \pm$ $0.02 \mathrm{~h}$ was obtained.

This research is funded by the Latvian Council of Science, project "Complex investigations of Solar System small bodies", project No. lzp-2018/1-0401.

\section{References}

Brown P.G. et al.: 2013, Nature, http://dx.doi.org/10.1038/nature12741.

Brian D.W.: 2016, Minor Planet Bull., 43, 240.

Milani A. et al.: 2012, Minor Planet Bull., http://belissima.aob.rs/Conf2012/Milani_2012.pdf

Skiff B.A. et al.: 2012, Minor Planet Bull., 39, 111.

Warner, B.D.: 2011, MPO Canopus software v10.2.1.0, http://www.minorplanetobserver.com/. 